\title{
The evaluation of medical and health resource allocation of public satisfaction in Songjiang Shanghai \\ ${ }^{1, a}$ Xujia $\quad{ }^{2, b}$ Liu qian $\quad{ }^{3, c}$ Wangwei
}

\author{
${ }^{1}$ Shanghai university of Engineering Science, School of Management Studies, ShangHai 201620, \\ China \\ ${ }^{2}$ Shanghai university of Engineering Science, The personnel department, ShangHai 201620, China \\ ${ }^{3}$ Shanghai university of Engineering Science, China and South Korea institute of multimedia colleg \\ e, ShangHai 201620, China \\ a,b,c xujia_may@yeah.net
}

Keywords: Evaluation ; medical and health r; public satisfaction ; Shanghai.

Abstract.

This paper is based on the appraisal model of medical and health resources that has been building already. Give priority to with the satisfaction of residents satisfaction and health practitioners to the medical and health resources allocation in China public satisfaction evaluation. It is concluded that the main factors influencing the health resource allocation, provide the basis for providing countermeasures and suggestions.

\section{Introduction}

This paper has built model to evaluate health system construction. To evaluate the status of the medical and health resources allocation, With residents satisfaction and subjective evaluation is given priority to health professionals. Data are from the author's first-hand research materials Due to the subjective satisfaction effect of hysteresis and data is acquired, only to comprehensive evaluation of 2013 year.

\section{The effect of public satisfaction index evaluation result}

The residents satisfaction effect evaluation: This questionnaire also adopts the self-evaluation of likert type 5 point scale method, namely, very satisfied, satisfied, general, dissatisfied, very dissatisfied, and in turn is divided into five points, 4 points, 3 points, 2 points, 1 points, the higher the score, indicates that the research object of the higher the degree of satisfaction Residents satisfaction questionnaires are out of 240, The effective recovery are 204 copies, The effective recovery rate was 85\%. Questionnaire survey locations as well as health professionals, mainly selected the pine, Xinqiao two more representative of the community health service centers and Songjiang center hospital.

The residents on health service level of satisfaction: The medical and health services project satisfaction overall is average 3.93 points .So we consider that residents of Songjiang district currently provide medical and health services are basically satisfied, infant care, maternal health, vaccine immunization of these basic medical and health services provide a better situation, in health supervision and management, occupational health surveillance, and mental health aspects still need to improve the service level, improve propaganda, exert good supervision responsibility, more residents to gain satisfaction.

Figure 2-1 Satisfaction of public health services to the of public health

$\begin{array}{lllllll}\text { Health service project } & \begin{array}{l}\text { satisfact } \\ \text { ion } 5\end{array} & \begin{array}{l}\text { satisfac } \\ \text { tion } 4\end{array} & \begin{array}{l}\text { satisfa } \\ \text { ction }\end{array} & \begin{array}{l}\text { satisfa } \\ \text { ction 2 }\end{array} & \begin{array}{l}\text { Satisf } \\ \text { actio }\end{array} & \text { mean } \\ \text { Infant health care } & 36.27 & 47.06 & 14.71 & 1.96 & 0 & 4.18\end{array}$


I Vaccine immunization immunization

immunization

Maternal care

Preventive health check-up

$\begin{array}{llllll}30.39 & 50.98 & 16.67 & 1.96 & 0 & 4.1\end{array}$

II Vaccine immunization

33.33

40.2

25.49

0.98

4.06

25.49

44.12

29.41

0.98

3.94

Outbreak of infectious diseases and

emergencies

24.51

41.18

34.31

0

30.39

30.39

37.2

1.96

3.89

Disease surveillance and control and prevention

27.45

33.33

38.2

0.98

3.87

Pre-marital health instruction and before

marriage

22.55

37.25

39.22

0.98

3.81

Medical examination health within the scope of authority

21.57

39.22

37.25

1.96

3.8

Food, and occupational health surveillance in public places

27.45

32.35

34.31

4.9

0.98

3.8

Mental health

22.55

26.47

43.14

7.84

3.64

The residents satisfaction of health professionals: According to the survey results show that the residents' satisfaction of health workers, the overall score of 4.08 points, suggests that the residents of the practitioners of health institutions, Songjiang district, rate higher. The diagnosis and treatment technology are the highest satisfaction, and satisfaction of waiting time is the minimum.

Figure 2-2 Satisfaction of public health practitioners from people

\begin{tabular}{llllllll}
\hline No. & item & S5 & S4 & S3 & S2 & S1 & mean \\
1 & Medical service attitude & 38 & 41 & 18 & 3 & 0 & 4.14 \\
2 & Communication situation & 35 & 47 & 15 & 3 & 0 & 4.14 \\
3 & Diagnosis and treatment technology & 38 & 45 & 12 & 5 & 0 & 4.16 \\
4 & & 29 & 39 & 27 & 5 & 0 & 3.92 \\
5 & Effect of service & 34 & 32 & 34 & 0 & 0 & 4 \\
\hline
\end{tabular}

The residents satisfaction the comprehensive effect of evaluation: According to the residents' satisfaction with two evaluation index "for the health service level satisfaction" and "satisfaction" for health practitioners two indicators according to the index weight to evaluate (see table 4-14), it is concluded that comprehensive score of 3.98 points, is a more satisfactory degree, illustrate the Songjiang district residents satisfaction effect is better.

Figure 2-3 Comprehensive index of people satisfaction

\begin{tabular}{lll}
\hline indicators & The weight & score \\
\hline The health service level of satisfaction & 0.6667 & 3.93 \\
Satisfaction of health professionals & 0.3333 & 4.08 \\
composite & & 3.98
\end{tabular}

The effect of health practitioners satisfaction evaluation: Health professionals construction of human resources is a big difficult problem in the construction of medical and health system of China, the grassroots health workers work load of volume is larger, more liquid, indirectly led to the lack of health service capability in, so this article will be the satisfaction of health practitioners also brought into effect evaluation index category.

Medical and health staff job satisfaction evaluation: From the research results, health care workers, the job satisfaction of overall average of 3.43 points, for the general satisfaction, including 
on the work itself, work surrounding relationship satisfaction is highest, to work to pay and the minimum volume of satisfaction.

This article USES the factor analysis method of principal component analysis (pca) to find out the key factor of health care workers, job satisfaction, in order to improve the satisfaction of medical and health care practitioners.

Reliability and validity analysis: Cronbach alpha coefficient is an important way to measure the reliability. In the medical and health care professionals, through the analysis of work satisfaction by using SPSS16.0 software for statistical data processing, get on job satisfaction of medical and health care practitioners Cronbach alpha coefficient is 0.923, also obtained the evaluation project standardized Cronbach alpha coefficient of 0.924. Reliability coefficient is greater than 0.800, therefore, that the survey evaluation table preparation of internal reliability is ideal

Table2-5 Reliability Statistics

\begin{tabular}{lll}
\hline Cronbach's Alpha & Cronbach's Alpha Based on Standardized Items & N of Items \\
.923 & .924 & 10 \\
\hline
\end{tabular}

The principal component analysis: The influencing factors of medical and health care professionals job satisfaction are various, such as: the work itself, personal growth and development, compensation and relationship maintenance, etc. Based on the questionnaire of the influence factors of setting questions, reference frame type definition, the employee job satisfaction is divided into four aspects: nature of work, working environment, work requirements, work development.

Inputting the variables of the survey in the SPSS16.0 software, using principal component analysis (pca) factor points coefficient matrix are obtained.

Table 2-6 Component Score Coefficient Matrix

\begin{tabular}{lllll}
\hline & \multicolumn{3}{l}{ Component } & \\
& 1 & 2 & 3 & 4 \\
X1:the work itself & .568 & -.296 & -.241 & .167 \\
X2: Development space & .271 & -.340 & .032 & .373 \\
X3: Security & .461 & .150 & -.070 & -.496 \\
X4: Compensation & -.323 & -.137 & .872 & -.027 \\
X5: The workload & -.007 & -.146 & .534 & -.073 \\
X6:Interpersonal relationships & -.157 & .625 & -.123 & -.167 \\
X7: Performance appraisal & .213 & .239 & -.076 & -.212 \\
X8: Management style & .093 & .133 & -.098 & .156 \\
X9: Involved in management decisions & -.232 & -.044 & -.069 & .771 \\
X10: Communication & -.240 & .531 & -.077 & .051 \\
\hline
\end{tabular}

Factor score can reflect each index variable and the relationship between the four main factors, scored higher on a main factor, indicates the relation between the indexes and the main factors closely, by rotating the away investments score coefficient matrix can write the composition of the expression, and compute the common factor scores.

$\mathrm{F} 1=0.568 \mathrm{X} 1+0.271 \mathrm{X} 2+0.461 \mathrm{X} 3-0.323 \mathrm{X} 4-0.007 \mathrm{X} 5-0.157 \mathrm{X} 6+0.213 \mathrm{X} 7+0.093 \mathrm{X} 8-0.232 \mathrm{X} 9-0.240 \mathrm{X}$ 10

$\mathrm{F} 2=-0.296 \mathrm{X} 1-0.340 \mathrm{X} 2+0.150 \mathrm{X} 3-0.137 \mathrm{X} 4-0.146 \mathrm{X} 5+0.625 \mathrm{X} 6+0.239 \mathrm{X} 7+0.133 \mathrm{X} 8-0.044 \mathrm{X} 9+0.531$

$\mathrm{X} 10$

$\mathrm{F} 3=-0.241 \mathrm{X} 1+0.032 \mathrm{X} 2-0.070 \times 3+0.872 \mathrm{X} 4+0.534 \mathrm{X} 5-.0123 \mathrm{X} 6-0.076 \mathrm{X} 7-0.098 \times 8-0.069 \times 9-0.077 \mathrm{X}$ 10

$\mathrm{F} 4=0.167 \mathrm{X} 1+0.373 \mathrm{X} 2-0.496 \mathrm{X} 3-0.027 \mathrm{X} 4-0.073 \mathrm{X} 5-0.167 \mathrm{X} 6-0.212 \mathrm{X} 7+0.156 \mathrm{X} 8+0.771 \mathrm{X} 9+0.051 \mathrm{X}$ 10

Let each of the common factor variance contribution rates of the four medical factor, the proportion of total variance contribution as a weighted function weighted calculation, draw the comprehensive evaluation function model: 
$\mathrm{Z}=(25.963 \mathrm{~F} 1+22.683 \mathrm{~F} 2+17.848 \mathrm{~F} 3+16.046 \mathrm{~F} 4) / 82.540$

We can see from the comprehensive evaluation function model, the factors influencing health care workers, job satisfaction importance to sort: nature of work, working environment, work requirements, development factor. To effectively solve the problem of high liquidity Songjiang district health care practitioners, from these four aspects to improve, improve the emphasis of medical and health work, improve the treatment level of medical and health care practitioners tend to be a doctor's treatment level, to improve coordination good working environment, and provide more opportunities for training, management.

Medical and health care practitioner analysis for the medical and health system satisfaction

Health care professionals for the medical and health system satisfaction total averaged 3.3 points, scored an average of almost every project above 3 points, Songjiang instructions in terms of medical and health system, the attitude of the medical and health care practitioners to 3 points of general satisfaction.

According to various projects, health care professionals in Songjiang district to provide medical and health service quality satisfaction score are the highest, followed by the medical and health system and health service satisfaction, in the income level of medical and health care professionals on the satisfaction of the lowest, that is only 2.87 points, less than half of three points satisfaction, which is to think in medical and health care practitioners income level is low, less investment, the income level of satisfaction is not high.

Figure 2-7 Satisfaction of public health workers to the public health system

\begin{tabular}{|c|c|c|c|c|c|c|}
\hline Item & S5 & $\mathrm{S} 4$ & S 3 & S2 & S11 & mean \\
\hline The quality of service & 15.96 & $\begin{array}{l}44.6 \\
8\end{array}$ & 30.85 & 6.38 & 2.13 & 3.66 \\
\hline Service project number & 9.57 & $\begin{array}{l}47.8 \\
7\end{array}$ & 28.72 & 11.7 & 2.13 & 3.51 \\
\hline System construction & 10.64 & $\begin{array}{l}39.3 \\
6\end{array}$ & 40.43 & 9.57 & 0 & 3.51 \\
\hline Personnel quality & 9.57 & $\begin{array}{l}31.9 \\
1\end{array}$ & 48.94 & 8.51 & 1.06 & 3.4 \\
\hline Function realization degree & 6.38 & $\begin{array}{l}42.5 \\
5\end{array}$ & 36.17 & 12.77 & 2.13 & 3.38 \\
\hline Government funding & 13.83 & 23.4 & 43.62 & 17.02 & 2.13 & 3.3 \\
\hline Number of devices & 5.32 & $\begin{array}{l}32.9 \\
8\end{array}$ & 41.49 & 18.09 & 2.13 & 3.21 \\
\hline Training learning opportunities & 4.26 & $\begin{array}{l}25.5 \\
2\end{array}$ & 47.87 & 19.15 & 3.19 & 3.09 \\
\hline The number of people & 5.32 & $\begin{array}{l}20.2 \\
1\end{array}$ & 48.94 & 22.34 & 3.19 & 3.02 \\
\hline Income level & 3.19 & $\begin{array}{l}12.7 \\
7\end{array}$ & 57.45 & 21.28 & 5.32 & 2.87 \\
\hline
\end{tabular}

Medical and health staff satisfaction comprehensive effects evaluation: According to the residents' satisfaction with two evaluation index "for the health service level satisfaction" and ", "satisfaction with healthcare professionals and two indicators according to the index weight to evaluate (see table 4-14), it is concluded that comprehensive score of 3.33 points, is a more satisfactory degree, lower than residents satisfaction the comprehensive effect of evaluation. Songjiang district medical and health care practitioners of health manpower, training opportunities, income level, management status still has a higher demand.

Figure2-8 Comprehensive index of satisfaction of public health workers

\begin{tabular}{lll}
\hline Indicators & The weight & score \\
\hline $\begin{array}{l}\text { Medical and health system } \\
\text { satisfaction }\end{array}$ & 0.75 & 3.3 \\
\hline
\end{tabular}




\begin{tabular}{lll}
\hline Job satisfaction & 0.25 & 3.43 \\
Composite & & 3.33
\end{tabular}

The public satisfaction the comprehensive effect of evaluation: According to the Public satisfaction of the two indicators of "residents satisfaction" and "satisfaction" medical and health care practitioners of the weighting and data, public satisfaction of Songjiang district in 2013 was 3.85 points (see table), the comprehensive effect of satisfaction for satisfactory degree, explain Songjiang district public satisfaction level is good.

Figure2-10 Comprehensive index of public satisfaciton

\begin{tabular}{lll}
\hline Indicators & The weight & score \\
\hline Residents satisfaction & 0.8 & 3.98 \\
The satisfaction of all medical and health care professionals & 0.2 & 3.33 \\
composite & & 3.85 \\
\hline
\end{tabular}

\section{The comprehensive evaluation on the effect of medical and health care system}

Because the public satisfaction is a qualitative indicators, is transformed into quantitative indicators need to determine the previous calendar year with reference to the average public satisfaction will be the index for standardization, due to unable to get the public satisfaction prior year data, in this article at present, the construction of the medical and health system only consider the effect of the comprehensive evaluation, mainly effect the health level of the evaluation.

Songjiang district health system construction effect in the health level of the objective indicators have a larger increase, medical and health system in 2007, three years operation, but there is still unstable; Subjective indicators in the public satisfaction degree of residents and medical health professionals' satisfaction on overall satisfaction is better, but residents of health supervision and management, occupational health surveillance there is still a pressing need and mental health, medical and health care practitioners to work business, pay, promotion, etc. There are still not satisfied.

(Fund project: The project are funded by "2013Shanghai universities young teacher training scheme"

Item number: ZZGJD12037)

\section{Reference}

[1]Xiaoyan li. Principal component analysis (pca) in the application of rural public health indicators evaluation [J]. Chinese health economy, 2007 (5) : 77 - a - 79.

[2]Wenke Wang. Public health resource allocation of government decision-making and fair. Chinese medical ethics, 2007, 20 (1) : 19-22

[3] Likun Pei. Australia's health system performance evaluation framework. Chinese journal of hospital management, 2004, 20 (8) : 510-512 